\title{
ANALISA RUTE DISTRIBUSI DAN BIAYA TRANSPORTASI SEBAGAI PENDUKUNG BISNIS PT POS INDONESIA KP BANJARNEGARA
}

\author{
Aditia Sovia Pramudita \\ Logistik Bisnis, Politeknik Pos Indonesia \\ e-mail: aditiasovia@poltekpos.ac.id
}

\begin{abstract}
PT Pos Indonesia is a state-owned enterprise engaged in courier service in Indonesia. To achieve the competitive advantage, PT Pos Indonesia certainly cannot be separated from its effectiveness and its efficiency in distributing letters and packages to the customers. This research is the background of the product distribution process at PT Pos Indonesia Regional VI Semarang which based on Pos Indonesia way, where the need for savings in needed. Therefore, the PROSAN section needs to make savings in terms of distribution routes and distance. The purpose of this study is to determine the distribution route of Pos Banjarnegara in order to minimize transportation costs. This research uses the VRP method. In this thesis, the VRP model is needed for the Banjarnegara Pos office distribution route, the solving for this method is to use saving matrix, nearest insertion, nearest neighbor and finding out the most effective VRP solving among those methods. Based on the calculation to complete the VRP using the saving matrix method, the total distance is $204,3 \mathrm{~km}$, the nearest insertion is 203,9, and the nearest neighbor produces a distance of 180,6 km while the current average for the distance in this company is $244,8 \mathrm{~km}$. This shows that the nearest neighbor method is more efficient in determining distribution routes, and this route can be done by using just one vehicle.
\end{abstract}

Keywords: saving matrix, nearest insertion, nearest neighbor, distribution, routes.

\section{A. Pendahuluan}

PT Pos Indonesia merupakan perusahaan BUMN yang bergerak dalam bidang jasa logistik. Pengiriman barang atau paket merupakan salah satu bagian penting dari 
model bisnis perusahaan ini. Suatu model bisnis yang baik tentunya perlu untuk memperhatikan berbagai faktor termasuk di dalamnya cost structure. Model bisnis yang seperti ini memiliki kepentingan terhadap jalur distribusi serta biaya transportasi yang sangat vital. Melalui jalur distribusi yang efisien, PT Pos Indonesia dapat memperoleh keunggulan kompetitif. Hal tersebut menunjukan pentingnya value chain di dalam menciptakan bisnis model yang berkelanjutan (Pramudita, 2018).

Unit Pelaksana Teknis Kantor Pos Banjarnegara Divisi Regional VI Semarang merupakan bagian dari perusahaan PT Pos Indonesia (Persero) yang bergerak di bisnis pelayanan jasa pengiriman barang milik pemerintah. Dalam menjalankan proses bisnisnya KP Banjarnegara dipimpim oleh seorang kepala kantor dan dibantu oleh 6 manajer yaitu, manajer dukungan umum, manajer pelayanan dan penjualan, manajer keuangan, manajer, akuntansi, manajer pengawasan unit pelayanan luar, dan terakhir adalan manajer proses dan antara (PROSAN). Setiap manajer telah memiliki job description masing masing yang telah di tetapkan oleh direktur. UPT Banjarnegara sendiri menjujung tinggi Top Key Goal (TGK) dari PT Pos Indonesia. TKG ini merupakan Pos Indonesia Way, dimana TKG ini harus dijalankan oleh Seluruh UPT yang ada.

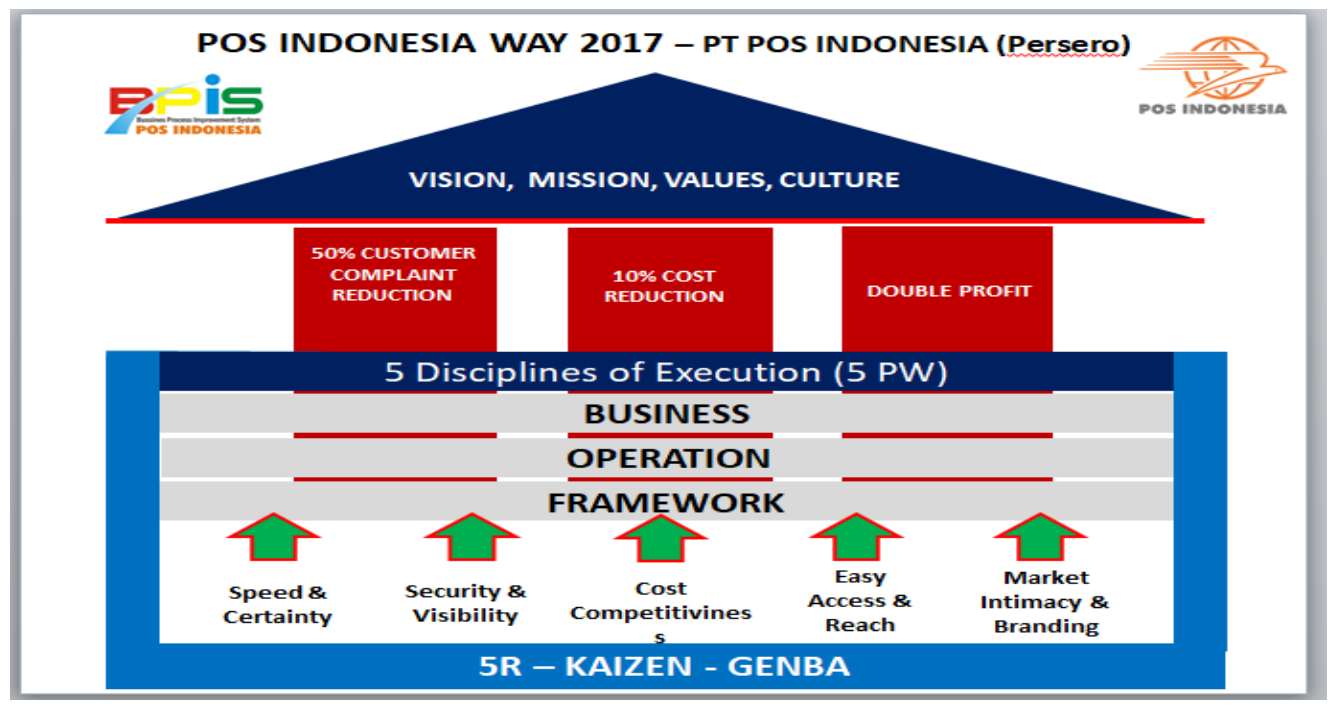

Gambar 1 Pos Indonesia Way

Sumber: PT Pos Indonesia, 2017

Belakangan ini seluruh managerial di UPT Banjarnegara sedang disibukkan oleh Cost Reduction. Cost reduction sendiri adalah suatu cara dimana PT Pos Indonesia 
melakukan penghematan, sehingga biaya operational dapat ditekan, hal ini dilakukan selayaknya perusahaan lain agar mendapat keuntungan yang lebih. Biaya operational merupakan variabel penyumbang angka HPP terbesar dalam setiap produk. Seluruh manajer yang menjabat saat ini diminta untuk melakukan penghematan atas biaya operasional yang ada di masing- masing bagian.

Bagian PROSAN dapat dikatakan merupakan jantung dari perusahaan ini karena pada bagian ini lah hampir terdapat seluruh kegiatan perusahaan mulai dari collecting, processing, transpoting, distibution, dan delivery tak heran uang operasional yang di dapat dibagian PROSAN pun sangatlah besar. Bagian PROSAN memiliki beberapa sub bagian diantaranya adalah bagian puri terima dan kirim, antaran, dan distribusi sehingga wajar bagian PROSAN merupakan bagian yang paling banyak jumlah karyawannya. Manajer PROSAN Banjarnegara memiliki 3 karyawan di sub puri, kemudian 18 karyawan di sub bagian antaran, dan 2 orang driver.

Proses pendistribusian untuk inbound dilakukan dengan menggunakan mobil Grand Max, saat ini UPT Banjarnegara memiliki 2 mobil Grand Max yang aktif dan 2 driver. Mobil ini diperuntukan untuk memenuhi 2 wilayah pendistribusian yaitu wailayah atas dan wilayah barat. Wilayah atas meliputi KPC Banjarmangu, KPC karangkobar, KPC Madukara, KPC Wanayasa, KPC Pejawaran, dan KPC Batur dan untuk wilayah barat meliputi KPC Bawang, KPC Purwonegoro, KPC Mandiraja, KPC Wanadadi, KPC Rakit, KPC Kelampok, dan KPC Susukan. Untuk menempuh semua kpc yang ada jalur barat dapat diselesaikan dengan waktu rata 2 sampai 2,5 jam dan untuk jalur atas dapat di tempuh dalam kurun waktu 3, 5 jam sampai dengan 4 jam.

\begin{tabular}{|c|c|c|c|c|c|}
\hline \multicolumn{6}{|c|}{ TAHUN 2017} \\
\hline \multirow{2}{*}{ no } & \multirow{2}{*}{ GULAN } & \multicolumn{3}{|c|}{ BLAYA BEN MNGIL GRAND NAX } & \multirow{2}{*}{$\begin{array}{l}\text { TOTAL } \\
\text { /BULAN }\end{array}$} \\
\hline & & H15732Q & D83270T & H1937WR & \\
\hline & LANUAAI & $2,750,000$ & $2,700,000$ & & $5,450,000$ \\
\hline & FEGAUAAI & $2,600,000$ & $2,600,000$ & & $5,200,000$ \\
\hline & MARET & $2,900,000$ & $2,900,000$ & & $5,800,000$ \\
\hline & APAIL & $2,650,000$ & $2,500,000$ & & $5,150,000$ \\
\hline & MEI & $2,600,000$ & $2,750,000$ & & $5,350,000$ \\
\hline & JUN & $2,750,000$ & $2,800,000$ & & $5,550,000$ \\
\hline & IUU & $2,900,000$ & & $2,900,000$ & $5,800,000$ \\
\hline & AGJSTUS & $2,850,000$ & & 2850,000 & $5,700,000$ \\
\hline & SEPTENGER & $2,800,000$ & & $2,650,000$ & $5,450,000$ \\
\hline & OKTOBER & $2,800,000$ & & $2,950,000$ & $5,750,000$ \\
\hline & NONENGER & $2,450,000$ & & $2,500,000$ & $5,250,000$ \\
\hline & DESENGER & $2,650,000$ & & $2,650,000$ & $5,300,000$ \\
\hline & TOTAL & $32,700,000$ & $16,250,000$ & $16,500,000$ & $65,750,000$ \\
\hline
\end{tabular}

\begin{tabular}{|c|c|c|c|c|}
\hline \multicolumn{5}{|c|}{ TAHUN 2018} \\
\hline \multirow{2}{*}{ No } & \multirow{2}{*}{ BULAN } & \multicolumn{2}{|c|}{ GIAYA BEM MOBIL GRAND MAXX } & \multirow{2}{*}{$\begin{array}{l}\text { TOTAL } \\
\text { /BULAN }\end{array}$} \\
\hline & & H 1678 ZQ & H 1937 W2 & \\
\hline & IANUAFI & $2,500,000$ & $2,650,000$ & $5,150,000$ \\
\hline & FEBRUARI & $2,650,000$ & $2,700,000$ & $5,350,000$ \\
\hline & MARET & $2,650,000$ & $2,550,000$ & $5,200,000$ \\
\hline & APRIL & $2,500,000$ & $2,550,000$ & $5,050,000$ \\
\hline & MEı & $2,753,400$ & $2,347,800$ & $5,101,200$ \\
\hline \multicolumn{5}{|c|}{\begin{tabular}{l|l}
6 & IUNI \\
\end{tabular}} \\
\hline \multicolumn{5}{|c|}{7 |JUL } \\
\hline \multicolumn{5}{|c|}{ 8 AGUSTUS } \\
\hline \multicolumn{5}{|c|}{ 9) SEPTEMBER } \\
\hline \multicolumn{5}{|c|}{\begin{tabular}{l|l|l|}
10 & OKTOBER \\
\end{tabular}} \\
\hline \multicolumn{5}{|c|}{ 11) NOVEMBER } \\
\hline \multicolumn{5}{|c|}{\begin{tabular}{l|l}
12 & OESEMBER \\
\end{tabular}} \\
\hline & TOTAL & $13,053,400$ & $12,797,800$ & $25,851,200$ \\
\hline
\end{tabular}




\section{Gambar 2 Pemaikan BBM 2017- 2018}

Sumber: KP Banjarnegara, 2018

Data tahun 2017 mencatat kedua mobil menggunakan anggaran Rp. 65.750 .000 untuk BBM, dari bulan Januari 2018 sampai bulan Mei 2018 telah terpakai uang sebesar Rp. 25.851.200. Dari gambar diatas terlihat bahwa pemakaian BBM setiap bulannya selalu berbeda-beda hal ini didasari dari tidak adanya jalur tetap atas jalur pendistribusian yang ada. Seringnya perubahan jalur ini disebabkan adanya surat dan paket yang diantar terlebih dahulu akan tetapi, sering juga jalur ini berubah karena permintaan suatu KPC akibat ingin didahulukan dari pada KPC yang lain. Pemakaian BBM terendah ada pada besaran Rp. 2,34 juta untuk satu mobilnya, sedangkan untuk nilai tertinggi berada pada nilai Rp. 2,95 juta /bulan. Hal ini harus dipertanyakan pasalnya wilayah jalur pendistribusian selalu tidak berubah. Hal ini sangat menyita perhatian penulis khususnya, sehingga timbul pertanyaan yang paling mendasar kenapa tidak setiap bulan penggunaan BBM tidak selalu stabil.

Permasalahan penentuan jalur distribusi ini banyak terjadi di perusahaanperusahaan. Permasalahan penentuan rute distribusi ini sering disebut sebagai Vehicle Routing Problem. Vehicle Routing Problem (VRP) adalah sebuah permasalahan dimana terdapat beberapa rute yang harus dilalui oleh sejumlah kendaraan yang berangkat dari suatu depot menuju beberapa tempat tujuan yang telah ditentukan dan berakhir pada depot yang sama. Permasalahan rute ini termasuk dalam Vehicle Routing Problem (VRP) yaitu permasalahan penentuan rute kendaraan untuk melayani beberapa pelanggan. Bentuk dasar VRP secara umum berkaitan dengan masalah penentuan suatu rute kendaraan (Vehicle) yang melayani suatu pelanggan yang diasosiasikan dengan node dengan demand atau permintaan yang diketahui dan rute yang menghubungkan depot dengan pelanggan, dan antar pelanggan yang lainnya (Toth \& Vigo, 2002).

\section{B. Metode Penelitian}

\section{Saving Matrix}

Disamping dapat memenuhi semua permintaan dari tiap KPC. Metode ini juga akan memberikan solusi rute dengan ongkos yang minimum, dikarenakan semakin besar nilai saving yang didapat dan didahulukan dalam membuat sebuah rute maka semakin besar 
pula penghematan yang dilakukan.Berikut disajikan algoritma penyelesaian (Sarjono, 2014).

Metode Clarke and Wright Saving Algorithm:

- Membuat matriks jarak yaitu matriks jarak antara KP Banjarnegara dengan KPC dan jarak antara masing- masing KPC. Pengukuran jarak dari titik A ke B dengan jarak titik B ke A sehingga matriks jarak ini termasuk matriks simetris. Bentuk umum matriks jarak ini dapat dilihat pada tabel 3.1 berikut:

Tabel 1 Bentuk Umum Matriks Jarak

\begin{tabular}{|c|c|c|c|c|c|c|c|}
\hline & $P_{0}$ & & & & & & \\
\hline$P_{0}$ & 0 & $P_{1}$ & & & & & \\
\hline$P_{1}$ & & & $P_{i}$ & & & & \\
\hline$P_{i}$ & $C_{0 i}$ & & & $\ldots$ & & & \\
\hline$\ldots$ & & & & & $P_{j}$ & & \\
\hline$P_{j}$ & & & $C_{i j}$ & & & $\ldots$ & \\
\hline$\ldots$ & & & & & & & $P_{n}$ \\
\hline$P_{n}$ & & & & & & & 0 \\
\hline
\end{tabular}

Sumber: (Pichpibul \& Kawtummachai, 2016)

Dimana $P_{0}=\operatorname{depot}$

$$
\begin{aligned}
P_{i} & =\text { titik ke } i \\
P_{j} & =\text { titik ke } j \\
C_{0 i} & =\text { jarak dari depot ke titik } i=\text { jarak dari titik } i \text { ke depot } \\
C_{i j} & =\text { jarak dari titik } i \text { ke titik } j=\text { jarak dari titik } j \text { ke titik } i .
\end{aligned}
$$

- Menghitung nilai penghematan $\left(s_{i j}\right)$ berupa jarak tempuh dari suatu kendaraan yang menggantikan dua kendaraan untuk melayani titik $i$ dan $j$.

$$
s_{i j}=c_{0 i}+c_{0 j}-c_{i j}
$$

\section{Keterangan :}

$s_{i j}=$ Nilai penghematan titik $i$ dan titik $\mathrm{j}$

$c_{0 i}=$ jarak dari depot ke titik $i=$ jarak dari titik $i$ ke depot

$c_{0 j}=$ jarak dari depot ke titik $j=$ jarak dari titik $j$ ke depot

$C_{i j}=$ jarak dari titik $i$ ke titik $j=$ jarak dari titik $j$ ke titik $i$. 
Nilai penghematan $s_{i j}$ adalah jarak yang dihemat jika rute $o$ - $i$ - $o$ digabungkan dengan $o$ $j$-o menjadi rute tunggal $o-i-j-o$ yang dilayani oleh satu kendaraan yang sama.

- Membuat matriks penghematan, dimana bentuk umum dari matriks penghematan yang dikembangkan oleh Clarke and Wright Algorithm dapat dilihat pada tabel 3.2 berikut:

Tabel 2 Bentuk Umum Matriks Penghematan

\begin{tabular}{|c|c|c|c|c|c|c|c|}
\hline & $P_{0}$ & & & & & & \\
\hline & 0 & $P_{1}$ & & & & & \\
\hline$\ldots$ & $C_{0 j}$ & & 0 & $\ldots$ & & & \\
\hline$q_{i}$ & & & & 0 & $P_{j}$ & & \\
\hline$q_{j}$ & & & $t_{i j} S_{i j}$ & & 0 & $\ldots$ & \\
\hline$\ldots$ & & & & & & 0 & $P_{n}$ \\
\hline$q_{n}$ & & & & & & & 0 \\
\hline
\end{tabular}

Sumber: (Pichpibul \& Kawtummachai, 2016)

$q_{i}$ adalah Permintaan titik ke $i$ dan $q_{j}$ adalah Permintaan titik ke $j$. Nilai-nilai dalam $t_{i j}$ menentukan apakah kombinasi $P_{i}$ dengan $P_{j}$ berada dalam satu rute. Petunjuk ini mempunyai nilai-nilai berikut jika titik tidak dihubungkan oleh satu rute kendaraan maka $t_{i j}=0$, jika dua titik dihubungkan pada satu kendaraan maka $t_{i j}=1$, jika titik dilayani tersendiri oleh satu kendaraan maka $t_{i j}=2$. Pemasukan (entries) $t_{i j}$ tidak ditunjukkan dalam matriks penghematan, pada awalnya tetapkan $t_{i j}=2$, yang berarti bahwa satu kendaraan dipakai untuk melayani masing-masing titik. Pada tahap ini proses berulang itu digerakkan sampai maing-masing matriks penghematan itu dievaluasi untuk perbaikan rute lebih lanjut. Prosedur ini adalah untuk mencari penghematan terbesar dari matriks ini berdasarkan kondisi yang berikut untuk setiap set $(i, j)$ :

1. $t_{i o}$ dan $t_{j o}=0$

2. $P_{i}$ dan $P_{j}$ belum dialokasikan pada jalur kendaraan yang sama.

3. Memperbaiki matriks penghematan, dengan memindahkan kendaraan kendaraan yang dialokasikan pada jalur $q_{i}$ dan $q_{j}$ serta menambah sebuah kendaraan untuk menutup jalur $q_{i}$ dan $q_{j}$ tidaklah menyebabkan kendaraan-kendaraan yang tersedia dalam setiap kolom dari matriks penghematan. 
- Memilih sebuah jalur dimana 2 rute yang dapat dikombinasikan menjadi satu rute tunggal. Sebuah nilai dari $t_{i j}=1$ ditempatkan dalam jalur itu, dan semua nilai $t_{i j}$ ke bawah kolom dimana $i=j$, adalah selalu sama dengan 2. Apabila $t_{i j}=0$, pasanglah $q_{j}=0$ dan buatlah $q_{j}$ sama dengan total jalur pada rute itu untuk semua $j$ yang lain.

\section{Nearest Insertion}

Merupakan metode yang digunakan untuk menyelesaikan masalah rute. Tidak jauh berbeda pada tahap awal metode ini menggunakan matriks jarak sebagai dasar perhitungan, matriks jarak ini seperti matriks jarak yang digunakan oleh metode saving matrix.

Tahap kedua ialah menentukan node pertama berdasarkan jarak paling dekat dengan depot, misalkan rute 1 memiliki 3 node $\mathrm{A}, \mathrm{B}$, dan $\mathrm{C}$ masing-masing node berjarak empat kilometer, tiga kilometer, dan lima kilometer sehingga terpilihlah node A sebagai node pertama yang dikunjungi.

Tahap ketiga adalah dimana tahap ini di ulangi sampai semua node sudah dikunjungi dan mejadi sebuah rute. Pada tahap ini menggunakan node sebelumnya menjadi acuan perhitungan (Utomo, Sa, \& Alam, 2018).

\section{Nearest Neighbor}

Nearest neighbor menggunakan matriks jarak sebagai acuan sama seperti metode yg lain. Pada tahap awal node terdekat menjadi node pertama yang dikunjungi. Kemudian node berikutnya dipilih node terdekat dari node terpilih dilihat dari matriks jarak (Elkan, 2014).

\section{Hasil dan pembahasan}

Berdasarkan perhitungan diatas penulis merangkumnya sebagai berikut :

Tabel 3 Perbandingan Perhitungan

\begin{tabular}{|c|c|c|c|c|c|}
\hline Kategori & $\begin{array}{c}\text { Kondisi } \\
\text { Awal }\end{array}$ & $\begin{array}{c}\text { Saving } \\
\text { Matriks }\end{array}$ & $\begin{array}{c}\text { Nearest } \\
\text { Insertion }\end{array}$ & $\begin{array}{c}\text { Nearest } \\
\text { Neighbor }\end{array}$ & $\begin{array}{c}\text { Rekomendasi } \\
\text { Terbaik }\end{array}$ \\
\hline Waktu tempuh & $8 \mathrm{Jam}$ & $5,39 \mathrm{Jam}$ & $5,24 \mathrm{Jam}$ & $4,71 \mathrm{Jam}$ & $\begin{array}{c}\text { Nearest } \\
\text { Neighbor }\end{array}$ \\
\hline Jarak & 244,8 & 204,3 & 203,9 & 180,6 & $\begin{array}{c}\text { Nearest } \\
\text { Neighbor }\end{array}$ \\
\hline
\end{tabular}




\begin{tabular}{|c|c|c|c|c|c|}
\hline Kategori & $\begin{array}{c}\text { Kondisi } \\
\text { Awal }\end{array}$ & $\begin{array}{c}\text { Saving } \\
\text { Matriks }\end{array}$ & $\begin{array}{c}\text { Nearest } \\
\text { Insertion }\end{array}$ & $\begin{array}{l}\text { Nearest } \\
\text { Neighbor }\end{array}$ & $\begin{array}{c}\text { Rekomendasi } \\
\text { Terbaik }\end{array}$ \\
\hline Biaya BBM / tahun & $65,750,000$ & $45,198,589$ & $45,110,095$ & $39,955,287$ & $\begin{array}{l}\text { Nearest } \\
\text { Neighbor }\end{array}$ \\
\hline $\begin{array}{c}\text { Penggunaan } \\
\text { Kendaraan }\end{array}$ & $\begin{array}{c}2 \\
\text { Kendaraan }\end{array}$ & $\begin{array}{l}\text { Memungkinkan } \\
\text { Untuk } \\
\text { Menggunakan } \\
1 \text { Kendaraan }\end{array}$ & $\begin{array}{l}\text { Memungkinkan } \\
\text { Untuk } \\
\text { Menggunakan } \\
1 \text { Kendaraan }\end{array}$ & $\begin{array}{l}\text { Memungkinkan } \\
\text { Untuk } \\
\text { Menggunakan } \\
1 \text { Kendaraan }\end{array}$ & $\begin{array}{c}\text { Saving } \\
\text { Matriks } \\
\text { Nearest } \\
\text { Neighbor } \\
\text { Nearest } \\
\text { Insertion }\end{array}$ \\
\hline
\end{tabular}

Tabel 4 Biaya BBM per Hari

\begin{tabular}{|c|c|c|c|c|c|}
\hline Metode & $\begin{array}{c}\text { Total } \\
\text { Jarak }\end{array}$ & Km/ L & $\begin{array}{c}\text { Pemakaian } \\
\text { Bbm / Hr }\end{array}$ & Harga /L & Biaya Bbm/ Hr \\
\hline Saving Matriks & 204,3 & 11 & 18,57 & 7,800 & 144,867 \\
\hline Nearest insertion & 203,9 & 11 & 18,54 & 7,800 & 144,584 \\
\hline Nearest neighbor & 180,6 & 11 & 16,42 & 7,800 & 128,062 \\
\hline
\end{tabular}

Tabel 5 Biaya BBM per Tahun

\begin{tabular}{|c|c|c|c|}
\hline Metode & Biaya Bbm/ Hr & $\begin{array}{c}\text { Biaya Bbm/ Bulan } \\
\text { (26 Hari Kerja) }\end{array}$ & Biaya Bbm/ Tahun \\
\hline Saving Matriks & 144,867 & $3,766,549$ & $45,198,589$ \\
\hline Nearest insertion & 144,584 & $3,759,175$ & $45,110,095$ \\
\hline Nearest neighbor & 128,062 & $3,329,607$ & $39,955,287$ \\
\hline
\end{tabular}

Penghematan dari keadaan awal saving matrix mampu menghemat $31,26 \%$, nearest insertion sebesar 31,39\%, dan nearest neighbor sebesar 39,32\%.

Ketiga cara penentuan node telah melebihi dari target penghematan sebesar $10 \%$ dengan rangking penghematan terbesar dari nearest neighbor, kedua yaitu nearest insertion, dan saving matrix. 
Dilihat dari segi perawatan mobil sendiri tidak ada yang berubah hal ini di karenakan oli, service, ban, dan perawatan untuk mesin seperti suku cadang lain yang banyak dipengaruhi oleh jarak tempuh. Akan tetapi ada satu hal yang kurang menguntungkan dari segi harga jual mobil, karena harga mobil secondpun biasanya dilihat dari segi jarak yang telah di tempuh oleh mobil tersebut. Makin rendah jarak tempuhnya atau angka yang ada di trip meter dapat mempertahankan harga jual yang tinggi, akan tetapi makin tinggi angka yang tertera pada trip meter maka harga mobilpun dapat berkurang. Mobil yang awalnya dipakai untuk proses pendistribusian dapat digunakan untuk kegiatan marketing atau pos keliling, yang diharapkan dengan adanya bantuan armada maka dapat menaikan pendapatan bagi Kantor Pos Banjarnegara.

Disisi HR perusahaan mampu meningkatkan angka produktifitas driver, teapi Kantor Pos Banjarnegara harus mempersiapkan cadangan driver hal ini harus dilakukan guna mengatisipasi keadaan yang mendesak. Dapat menekan angka gaji pegawai sebesar Rp. 1,5 juta / bulan atau dapat menerima pegawai untuk bagian yang lain yang masih membutuhkan SDA.

Tabel 4.29 Perbandingan Satu Kendaraan dan Dua Kendaraan

\begin{tabular}{|c|c|c|c|}
\hline \multirow{2}{*}{ No } & \multirow{2}{*}{ Kategori } & \multicolumn{2}{|c|}{ Kondisi } \\
\hline & & Satu Kendaraan (Rekomendasi) & Dua Kendaraan (Kondisi Awal) \\
\hline 1 & Pemakaian BBM & Rp. 128.061 perhari & Rp. 128.061 perhari \\
\hline 2 & Biaya perawatan & sama dengan kondisi sebelumnya & sama dengan kondisi sebelumnya \\
\hline 3 & Gaji driver & $\begin{array}{l}\text { lebih hemat. Penghematan bisa } \\
\text { mencapai Rp. } 18 \text { juta }\end{array}$ & sama dengan kondisi awal \\
\hline 4 & Skema distribusi & $\begin{array}{l}\text { rute diselesaikan satu persatu. } \\
\text { Tidak dapat dilakukan secara } \\
\text { bersama. Sehingga memerlukan } \\
\text { waktu lebih lama dari pada } \\
\text { kondisi awal. }\end{array}$ & $\begin{array}{l}\text { kedua rute dapat dilakukan secara } \\
\text { bersama, sehingga proses } \\
\text { pendistribusian dapat dilakukan } \\
\text { dengan cepat }\end{array}$ \\
\hline 5 & Muatan/ kapasitas & $\begin{array}{l}\text { tetap sama dengan kondisi awal } \\
\text { karena setiap penyelesaian suatu } \\
\text { rute kendaraan kembali lagi ke } \\
\text { depot untuk loading barang rute } \\
\text { selanjutnya }\end{array}$ & $\begin{array}{l}\text { sama seperti kondisi awal, untuk } \\
\text { kapasitas tidak ada yang berubah }\end{array}$ \\
\hline
\end{tabular}




\section{Kesimpulan}

1. Berdasarkan hasil pengolahan data yang penulis sajikan pada bab IV, ada beberapa rute yang digunakan driver Kantor Pos Banjarnegara Regional VI Semarang untuk mendistribusikan produk surat dan paket wilayah kabupaten Banjarnegara. Berikut adalah rute rekomendasi pendistribusian KPBA

a. Wilayah atas: Kantor Pos Banjarnegara - Banjarmangu - Madukara Pejawaran - Batur - Wanayasa - Karangkobar - Kantor Pos Banjarnegara.

b. Wilayah barat: Kantor Pos Banjarnegara - Bawang - Wanadadi - Rakit - Mandiraja - Purwonegoro - Kelampok - Susukan - Kantor Pos Banjarnegara.

2. Penghematan yang dilakukan denan rute rekomendasi saving matriks adalah sebesar 39,23\% dari target $10 \%$ sehingga apabila KP Banjarnegara menerima usulan ini KP Banjarnegara hanya perlu mengeluarkan biaya BBM sebesar Rp. 39,955,287,- dari sebelumnya sebesar Rp. 65,750,000,-. Dengan simulasi berdasarkan rute rekomendasi diatas KP Banjarnegara hanya memerlukan 1 driver. Seorang driver memiliki waktu kerja sebesar 7,5 jam / hari sedangkan untuk menempuh rute rekomendasi baik wilayah atas dan barat hanya memerlukan waktu 4 jam 43 menit. Apabila KP Banjarnegara mengikuti usulan maka penghematan dari segi gaji pegawai sebesar Rp. 18,000,000,- selama satu tahun.

\section{E. Referensi}

Elkan, C. (2014). Nearest Neighbor Classification, (June). https://doi.org/10.1007/9780-387-39940-9

Pichpibul, T., \& Kawtummachai, R. (2016). An improved Clarke and Wright savings algorithm for the capacitated vehicle routing problem, (September 2012). https://doi.org/10.2306/scienceasia1513-1874.2012.38.307

Pramudita, A. S. (2018). Formulasi Model Bisnis Hostel di Bandung dengan Pendekatan Value Chain dan Business Model Canvas ( Studi Kasus: Pinisi Backpacker ), II(1), 32-38. 
Toth, P. and Vigo, D. 2002. The Vehicle Routing Problem. Siam, Philadelphia. http://dx.doi.org/10.1137/1.9780898718515

Sarjono, H. (2014). Determination of Best Route to Minimize Transportation Costs Using Nearest Neighbor Procedure, 8(62), 3063-3074.

Utomo, R. G., Sa, D., \& Alam, C. N. (2018). Implementasi Algoritma Cheapest Insertion Heuristic ( $\mathrm{CIH}$ ) dalam Penyelesaian Travelling Salesman Problem ( TSP ), 3(1), 61-67. https://doi.org/10.15575/join.v3i1.218 